\section{BMJ Paediatrics Open}

\title{
Impact of COVID-19 on the lives of vulnerable young people in New Delhi, India: a mixed method study
}

Sharanya Napier-Raman, ${ }^{1}$ Ananya Rattani, ${ }^{2}$ Yawar Qaiyum, ${ }^{2}$ Vijayluxmi Bose, ${ }^{2}$ Rajeev Seth, ${ }^{2,3}$ Shanti Raman (1) ${ }^{4,5}$

To cite: Napier-Raman S, Rattani A, Qaiyum Y, et al. Impact of COVID-19 on the lives of vulnerable young people in New Delhi, India: a mixed method study. BMJ Paediatrics Open 2021;5:e001171. doi:10.1136/ bmjpo-2021-001171

- Additional supplemental material is published online only. To view, please visit the journal online (http://dx.doi.org/ 10.1136/bmjpo-2021-001171).

Received 26 May 2021 Accepted 9 July 2021

\section{Check for updates}

(c) Author(s) (or their employer(s)) 2021. Re-use permitted under CC BY-NC. No commercial re-use. See rights and permissions. Published by BMJ.

${ }^{1}$ Faculty of Medicine and Health The University of Sydney, Sydney, New South Wales, Australia

${ }^{2}$ Bal Umang Drishya Sanstha, New Delhi, India

${ }^{3}$ International Society for Prevention of Child Abuse and Neglect, New Delhi, India ${ }^{4}$ Department of Community Paediatrics, South Western Sydney Local Health District, Liverpool, New South Wales, Australia

${ }^{5}$ School of Women's and Children's Health, University of New South Wales, Sydney, New South Wales, Australia

Correspondence to Dr Shanti Raman; shanti. raman@health.nsw.gov.au

\section{ABSTRACT}

Background India is home to the largest child population in the world. India also has faced a devastating burden of COVID-19 infections. During the first wave of COVID-19, the Indian government's lockdown measures brought loss of livelihoods for millions. We aimed to explore the social, psychological and health impacts of the government's pandemic measures on children and young people (CYP), and their families.

Methods Bal Umang Drishya Sanstha (BUDS) is a nonprofit organisation providing child health and welfare services to marginalised urban slum communities in New Delhi, India. As part of formative evaluation of BUDS's COVID-19 pandemic relief efforts, the team conducted a rapid survey of 60 children (10-17 years) and 62 young adults (18-25 years) who were beneficiaries of the relief programme. The team also undertook semi-structured interviews with nine young women attending BUDS's second-chance education programme.

Results Almost all respondents had some understanding of COVID-19 (54 children (90\%) and 53 young adults $(85 \%))$ and the reasons for public health measures (59 children (98\%) and 56 young adults $(90 \%))$. Over $80 \%$ of girls and $60 \%$ of boys experienced financial strains and food shortages. Gender discrepancies were particularly evident in areas of family stress, with girls and young women disproportionately experiencing distress and family violence. Girls were more likely to be fearful of contracting the disease, while boys were more concerned about getting back to school. In-depth interviews with young women revealed that government ration schemes were insufficient to support vulnerable families; there were interesting cultural understandings of and responses to the pandemic. Young women reported high rates of anxiety and distress.

Conclusions The lockdown had a multitude of adverse social, health and psychosocial effects on marginalised CYP, disproportionately affecting girls and young women. A tailored response based on equity and child rights is urgently required to address concerns voiced by CYP.

\section{INTRODUCTION}

The new public health crises borne from the emergence and spread of the 2019 novel coronavirus (SARS-CoV-2), or COVID-19, are truly global in presence and impact. As of early 2021, there have been over 100 million

\section{What is known about the subject?}

COVID-19 disproportionately impacts health systems in low-income settings and the health of the most marginalised populations.

- While children and young people are less likely to suffer direct impacts from COVID-19, they experience heightened adversity due to indirect effects and social control measures.

- The most crucial concerns for children in India during the pandemic were the lack of money, food, livelihoods, discontinuation of education and adverse impacts on health.

\section{What this study adds?}

The pandemic-related lockdown had a multitude of adverse social, health and psychosocial effects on vulnerable children and young people (CYP) from the urban slums of New Delhi.

> The most pressing concern for CYP was financial strain and loss of livelihoods.

- There were significant gender differentials in the impact of the pandemic and lockdown, with girls and young women bearing the brunt of psychological and economic stress.

cases of COVID-19, two million deaths and estimates of future deaths numbering in the millions. ${ }^{12}$ Governments across the world have adopted several mitigation strategies such as hygiene measures, social distancing and, in many cases, total lockdown. Despite such measures, COVID-19 outbreaks have disproportionately impacted health systems in low-income settings. ${ }^{3}$ Anticipation of the severe economic burden of a global pandemic has prompted calls for greater public health investment in poor countries. ${ }^{4}$ A concern has been the way pandemic responses have perpetuated a 'false dichotomy' between saving lives and saving livelihoods. ${ }^{5}$

Globally, there are significant concerns about children and young people's (CYP) 
well-being as a result of the pandemic. ${ }^{6}$ While the virus impacts relatively few children through severe morbidity or mortality, CYP experience heightened adversity as governments intervene with drastic social control measures. At the peak of the pandemic, an unprecedented 1.6 billion children were out of school, with concerns that widespread economic insecurity would increase rates of children's exploitation, labour, maltreatment and teenage pregnancy. ${ }^{7}$ Modelling suggests increases in child and maternal deaths globally, ${ }^{8}$ along with significant mental health and psychosocial consequences of pandemic measures. ${ }^{9}$ In CYP, lifestyle disruptions implemented in a short time-frame have inadvertently exposed a darker social scenery that challenges well-being of a whole generation of young people. ${ }^{10}$

India has the world's largest child population. With respect to COVID-19, India has the second highest burden of cases globally. ${ }^{1}$ The Indian government's early lockdown measures ranked as among the most stringent in the world, and caused losses of livelihood and income of $>400$ million daily wage earners in the informal economy. ${ }^{11}$ Save the Children, India, reporting on family challenges due to COVID-19 pandemic response in 2020, found the most crucial concerns were lack of money, food, livelihoods, discontinuation of children's education and adverse impacts on health. ${ }^{12}$ Bal Umang Drishya Sanstha (BUDS) is a non-for-profit organisation working to advance the health, well-being and welfare of vulnerable children in India, focusing on those experiencing extreme poverty. Current sites of activity include two urban settlements in New Delhi and one rural population. One of BUDS's targeted programmes is Parwaaz Adolescent Centre for Education (PACE), which provides second-chance education to adolescent girls who lack access to formal education. BUDS's response to the COVID-19 pandemic and the government's containment measures involved reaching out to underprivileged migrants and daily wage earners, supplementing government relief and health promotion. We undertook this study with CYP who are regular users of BUDS's services, as formative evaluation and assessment of the COVID-19 relief effort. Our aims were to identify what CYP know about COVID-19; determine the social, psychological and health impacts of the government mandated lockdown; explore gender and age differentials in response to COVID-19; and identify CYP's coping strategies during the pandemic.

\section{METHODS}

This was a mixed methods study to provide a robust understanding of CYP's experiences.

\section{Quantitative}

A brief evaluation tool, the Rapid Assessment Questionnaire (RAQ) was developed by BUDS's staff to gather information about issues facing young people, based on fieldworkers' experiences of concerns raised, while delivering relief supplies (see online supplemental appendix 1). In consultation with the research support team in Australia, the questionnaire was further refined. RAQs were conceptualised in English then translated to Hindi, using simple, direct language, by bilingual staff. RAQs included simple demographic information such as age, gender, family size and socioeconomic information. Other questions were related to participants' understandings of COVID-19, the problems faced during lockdown and access to relief and assistance during lockdown. RAQs were administered by BUDS's field staff trained to conduct questionnaires over telephone.

The sample was determined by the number of eligible participants who could be interviewed within time constraints as mandated by urgent need. Participants were derived from the list of BUDS's beneficiaries, those from Sarai Kale Khan or Mori Gate were selected. Both areas have mixed Muslim and Hindu populations, mostly low-income daily wage labourers and informal workers. From this list, children aged 10-18 years and young adults aged 18-25 years were selected. Efforts were made to involve both males and females, although there were far greater young women BUDS's beneficiaries. From this sample, participants were chosen based on a random numbers selection process.

RAQs were administered to 122 individuals-60 children (aged 10-17 years) and 62 young adults (aged 18-25 years), respectively.

\section{Qualitative}

In-depth semi-structured interviews were conducted during the first 'unlock' period following the initial lockdown. Nine young women (18-25 years), also from the areas of Mori Gate and Sarai Kale Khan, who were beneficiaries of the on-going PACE programme were purposively selected.

A semi-structured interview guide was developed collaboratively with BUDS's field staff. Questions investigated the following themes:

- Participants' views of the reason for lockdown.

- Participants' personal experience of the lockdown.

- Provision of food and relief by BUDS.

- Home environment during the lockdown.

- Education and the lockdown.

- Experiences of the lockdown (including domestic and family violence)

- Information on COVID-19 (including sources of information).

All interviews were conducted in Hindi and were recorded after establishing participants' consent. Out of the nine interviews, five were transcribed into English by a professional agency to aid analysis. Budgetary constraints limited our ability to translate the remainder.

\section{Analysis}

Quantitative

We carried out simple descriptive statistical analysis of the data collected via the RAQ, using Stata V.16. ${ }^{13}$ Due to the 
Table 1 Top concerns of children regarding COVID-19-gender comparison

\begin{tabular}{llll}
\hline Concerns & Girls (N=30) & Boys (N=30) & P value \\
\hline Money shortage & $100 \%$ & $50 \%$ & $<0.001^{*}$ \\
\hline Food/essential supply shortage & $80 \%$ & $63.3 \%$ & 0.2516 \\
\hline Boredom & $100 \%$ & $36.7 \%$ & $<0.001^{*}$ \\
\hline Fear of contracting COVID-19 & $76.7 \%$ & $20 \%$ & $<0.001^{*}$ \\
Unable to see friends & $50 \%$ & $50 \%$ & 1 \\
\hline Uncertainty around being able to return to school/ work & $32.5 \%$ & $43.3 \%$ & 0.5959 \\
\hline Family ignoring their needs & $83.33 \%$ & $16.7 \%$ & $<0.001^{*}$ \\
\hline Fights with siblings & $66.7 \%$ & $6.7 \%$ & $<0.001^{*}$ \\
\hline Violence/anger from family members & $46.7 \%$ & $6.7 \%$ & $<0.001^{*}$ \\
\hline
\end{tabular}

Tests of significance: Fisher's exact Test.

*Significant difference.

small sample size, we used Fisher's exact test to explore differences in responses based on gender.

\section{Qualitative}

We undertook thematic analysis of the in-depth interviews, and supporting iterative ethnographic reports from the field. ${ }^{14}$

We triangulated the findings from the quantitative and qualitative analysis, including information from the Hindi-only interviews, in order to develop an extensive understanding of the context and experiences of CYP.

\section{RESULTS}

Quantitative

Sixty children ( $<18$ years), including 30 girls (mean age: 14 years) and 30 boys (mean age: 13 years), and 62 young adults (19-25 years), including 40 young women (mean age: 21 years) and 22 young men (mean age: 22 years), completed RAQs. Table 1 lists the main concerns elicited by the rapid assessment of boys and girls and table 2 lists the main concerns elicited from young men and women. There were significant gender differences in the responses. Table 3 lists the responses to questions regarding COVID-19, including knowledge and sources of information. Most CYP knew about COVID-19 and reasons for public health measures. CYP reported the following support from BUDS: receipt of rations by majority of respondents (29 boys and 30 girls; 21 young men and 39 young women) and information on government programmes ( 9 boys and 21 girls; 3 young men and 22 young women).

\section{Qualitative: integrated themes}

Knowledge and understanding of the pandemic: 'I would tell you that there has not been any benefit from the lockdown ... rather the condition of people got worse' (Anuja) (All names have been changed in order to preserve confidentiality).

Participants had basic COVID-19 literacy, with varying depths of understanding. All young women knew about preventative measures of distancing, isolation and general hygiene. Despite knowledge of preventative measures, implementing these measures proved less tenable. All participants lived in single-room dwellings with up to five other people, making distancing at home impossible. Gowri had repeated difficulties getting water during the lockdown, noting 'sometimes we got the water, and sometimes we did not get the water. Sometimes we had to stay without water'.

Young women also revealed interesting cultural understandings of the pandemic and illness. Rachna, who fell sick during lockdown, was subject to social alienation and

Table 2 Top concerns of young people regarding COVID-19-gender comparison

\begin{tabular}{llll}
\hline Concerns & $\begin{array}{l}\text { Young adult females } \\
\mathbf{N}=\mathbf{4 0}\end{array}$ & $\begin{array}{l}\text { Young adult males } \\
\mathbf{N = 2 2}\end{array}$ & P value \\
\hline Money shortage & $97.5 \%$ & $90.90 \%$ & 0.2516 \\
Food/ essential supply shortage & $52.5 \%$ & $81.81 \%$ & 0.285 \\
Boredom & $87.5 \%$ & $31.81 \%$ & 0.029 \\
Fear of contracting COVID-19 & $72.5 \%$ & $27.27 \%$ & $0.001^{*}$ \\
Unable to see friends & $69.23 \%$ & $36.36 \%$ & $0.001^{*}$ \\
Uncertainty around being able to return to school/ work & $32.5 \%$ & $54.54 \%$ & $0.015^{*}$ \\
\hline
\end{tabular}

Tests of significance: Fisher's Exact Test.

*Significant difference. 
Table 3 Children and young peoples' knowledge of and attitudes towards COVID-19

\begin{tabular}{lllllll}
\hline & $\begin{array}{l}\text { Female children } \\
(\mathbf{n}=\mathbf{3 0})\end{array}$ & $\begin{array}{l}\text { Male children } \\
(\mathbf{n}=\mathbf{3 0})\end{array}$ & $\mathbf{P}$ value & $\begin{array}{l}\text { Female young } \\
\text { adults }(\mathbf{n}=\mathbf{4 0})\end{array}$ & $\begin{array}{l}\text { Male young } \\
\text { adults }(\mathbf{n}=\mathbf{2 2})\end{array}$ & $\mathbf{P}$ value \\
\hline Know reason for lockdown & 96.7 & 100 & 0.99 & 85 & 100 & 0.08 \\
\hline Know about COVID-19 & 83.3 & 96.7 & 0.195 & 77.5 & 100 & $0.02^{*}$ \\
\hline $\begin{array}{l}\text { Able to identify symptoms } \\
\text { Knowledge sources }\end{array}$ & 90 & 66.7 & 0.058 & 87.5 & 95.5 & 0.41 \\
$\quad \begin{array}{l}\text { Television } \\
\text { Social media }\end{array}$ & 90 & & & & & \\
$\quad$ Community and family & 10 & 70 & 0.1 & 85 & 86.4 & 0.99 \\
\hline
\end{tabular}

All figures provided are in percentages.

Tests of significance: Fisher's exact test.

*Significant difference.

stigma from people in her building. Neighbours would run away from her and claimed her sudden incapacitation was due to madness. When her tests came back negative for COVID-19, Rachna and her family decided her illness had paranormal causes and that the spirit of a man who had died in Rachna's building was tormenting her.

Information sources and access to health: 'I waited for about an hour and no ambulance came' (Rachna).

Television broadcasts and public service announcements were the most commonly noted information sources. All participants cited BUDS as a key source of information, particularly in explaining the pandemic. Interviews also revealed significant gaps in access to medical care and support. When Rachna fell sick, she visited two private hospitals, neither of which succeeded in diagnosing her. She then visited a Mohalla Clinic (government-funded clinic) where she was told that she had COVID-19 symptoms and needed to be hospitalised. Rachna was refused admission and informed that a special COVID-19 ambulance would come instead, which never arrived. Similarly, Meena, who was pregnant during lockdown, experienced inadequate medical support, receiving no prenatal care and missing her vaccinations.

Financial strain: 'The biggest problem we faced was financial problem' (Gowri).

Young women reported that financial strain was the most significant impact of the lockdown. All participants mentioned job loss and money shortages in their home environments. Food and essential supply restrictions, aggravated by financial strain, was a significant impact of lockdown. Anuja, who gave birth during the lockdown, was unable to breastfeed her child, being too weak and undernourished. She struggled instead to buy milk for her baby, asking 'how would I be able to get the adequate food and nutrition that I should get right now? We are hardly able to afford the carton milk'.

Interviews exposed government ration schemes as insufficient, unreliable and unclear. Anuja commented, 'the government has launched scheme of distributing ration etc, but we did not receive it'. Meena, who did receive rations, found them inadequate, stating they gave 'rice and wheat, but how a family can manage its meal with just that?'. Participants' responses revealed large discrepancies in what individuals received and a complete lack of information regarding what families were entitled to. Rachna complained that she received no help from the government and had no knowledge of any relief schemes. She noted that when her family tried to receive COVID-19 relief rations, they were turned away.

Inability to pay rent was another crucial impact of the lockdown-induced economic collapse, with many families completely subject to landlords' discretion. While Rachna's landlord waived her family's rent for the first month of lockdown, he then began to behave 'so insanely' and insisted on payment, despite all of Rachna's family having lost their jobs. Anuja's landlord refused to 'waive-off even a single rupee', while Sushma admitted to being unable 'to pay even a single a rupee as rent' in the last 4 months.

Psychosocial distress: 'I feel that my mind is going to blast like a bomb' (Sushma).

Young women reported extreme levels of emotional distress triggered by lockdown. Participants suffered boredom and loneliness, expressing frustration at being unable to study or meet friends. Young women struggled with the loss of independence previously gained from working. Sushma, who was being pressured to marry due to her inability to study or work during lockdown, divulged she spent hours crying every day. She received daily phone calls from her father harassing her to come to his village and marry. 'Because of the tension', Sushma frequently skipped meals and would sleep for only 3 hours each night.

While none of the young women explicitly mentioned physical violence at home, aggression and stress brought by financial strain and close proximity were evident. All women used the term 'tension' to allude to varying levels of familial dysfunction that may have included violence and abuse. Gowri was a victim of marital rape. Not having any financial support or money for contraceptives, Gowri tried to refuse intercourse, but 'that man (her husband) didn't agree' and forced her. Meena noted her husband would shout at her regularly. Sushma, on top of pressure 
to marry, spoke of constant tension between family members from being trapped inside together.

Desire to study/return to school: 'I feel that the dreams which I had seen, they are breaking because my studies are not starting' (Sushma).

Participants expressed keen desire to return to their education that had been curtailed by the lockdown. Young women all declared frustration and depression at being unable to study and work, and missed social interaction of peers at their learning centre. Those who tried to study at home found it impossible to concentrate with the increased financial, social and familial strain of lockdown. Participants felt that they were robbed of hope and of the purpose they had previously gained from studying. Trapped at home with her impending marriage, Sushma lamented, 'whatever dreams and aspirations I had, they started going away from me, and the household work started coming closer to me'. Participants noted that because they were women, their families treated their educational and vocational ambitions as a 'luxury' that, under the pressure of lockdown, was secondary to family duties.

\section{DISCUSSION}

Our study, which aimed to provide rapid feedback and evaluation of BUDS's grassroots relief work in New Delhi, has yielded valuable insights into the experiences and needs of CYP on the margins. Early in the pandemic, World Vision's 'Listening to children in the context of COVID-19' documented young people's experiences across 13 countries. ${ }^{15}$ Respondents highlighted school disruption, emotional distress due to social distancing and increasing poverty as factors impacting their lives. There were many similarities in our study, indeed CYP experiences across many low resource settings share common features-curtailment of rights, ${ }^{16}$ increased experiences of distress, violence, ${ }^{17} 18$ extreme financial insecurity ${ }^{19}$ and missing out on education. ${ }^{20} \mathrm{~A}$ distinct finding in our study was that gender differences were striking. Girls and young women felt more fear, distress, boredom, concern for family members and conversely effects of family violence and abuse, whereas boys were more concerned about returning to school or work. This formative research has provided invaluable guidance to the ongoing relief operations and counselling services that BUDS has delivered, during the first and second waves of COVID-19 in India.

In terms of knowledge of COVID-19 and the reasons for lockdown, almost all participants had some understanding, though depth of knowledge varied. We found that CYP had knowledge of why lockdown measures were being undertaken as well as general COVID-19 literacy, and they coped with the constraints. While general safety measures such as hand washing, wearing face masks and keeping distance were broadly known, they were not necessarily practicable. The most common information source for participants was TV news coverage and health announcements. Girls and young women also sited BUDS as providing information on government programmes. Males appeared more confident in their knowledge of COVID-19. Cultural explanations of illness and symptomatology voiced by young women provided a way of making sense of and destigmatising an otherwise inexplicable illness.

Both quantitative and qualitative analysis revealed financial strain as the most prevalent impact of pandemic measures. The RAQs exposed the impacts of the lockdown in terms of shortage, with high numbers of affirmative responses to questions of money, food and essential supply shortages. Interview participants elaborated on these issues of food shortage and limited resources. Not only was food shortage a recurrent issue for young women, but also the quality and nutritional value of foodstuffs. One young woman reported being unable to afford adequate nutrition to breastfeed her baby, others worried about being able to feed their families. The interviews further revealed that government relief failed to mitigate food insufficiency brought by lockdown, with ration programmes being piecemeal, inadequate and opaque. There was little clarity about what families were entitled to, nor how to access this. Housing insecurity was a crucial effect of the lockdown, with no clear government policy on rent waiving affecting many families.

Gender discrepancies in the experience of lockdown were particularly evident in areas of family strain and dysfunction. All of the young women interviewed indicated extreme levels of psychological distress. In the RAQs, females were significantly more likely than males to respond affirmatively to feelings of boredom and aggression and arguments among their families. Furthermore, in the RAQs, all of the young girls and the majority of young women and men responded positively to having experienced money shortage, whereas only half the young boys did so. This implies that females are more exposed to household pressures and experience financial deprivation at an earlier age than their male counterparts. Young women reported that with the suspension of work and education, housework and chores had become the central part of their days. Chakraborty notes that the unequal gendered division of domestic chores existed before the onset of the pandemic, but that COVID-19-induced lockdowns had dramatically worsened the situation. ${ }^{21}$ There is severe gender inequity in secondary and higher level education as findings from the Young Lives in India conclusively proved. ${ }^{22}$ Interviews included accounts of marital rape, allusions to family violence and threats of being forced into marriage, all aggravated by the lockdown. Young women thus faced not only the burdens of draconian lockdown measures, but the loss of aspirations and their futures. The role of gender in health disparity in South Asia is well documented, with gender discrimination contributing at each stage of the female life cycle. ${ }^{23}$

\section{CONCLUSION}

This study conducted at the tail end of the first lockdown in the urban slums of New Delhi describes the myriad negative effects on CYP, especially girls and women, as 
voiced by CYP. We know that mothers and childrenespecially in the poorest countries-are suffering significant indirect impacts on health and care due to COVID19 , with potentially long-term adverse effects. ${ }^{24}$ We know of the acute indirect effects of the pandemic on the poor, and we know that protecting the poor makes economic sense. ${ }^{25}$ The International Child Health Group (Royal College of Paediatrics and Child Health) recommends that COVID-19 recovery efforts must prioritise a new era of investment in robust health systems supporting a family-centred model of healthcare and child health programmes. ${ }^{24}$ To this we add, a tailored, gender-sensitive response must address concerns voiced by CYP on the margins, and be based on equity and child rights.

Contributors All co-authors contributed to the planning, conceptualisation and writing up of the project. SN-R and AR did the main data collation and analysis. SN-R and SR did the final editing of the document.

Funding The authors have not declared a specific grant for this research from any funding agency in the public, commercial or not-for-profit sectors.

Competing interests No, there are no competing interests.

Patient consent for publication Not required.

Ethics approval This study was approved as a COVID-19 emergency evaluation by the independently appointed Bal Umang Drishya Sanstha's Institutional Review Board (document ID: BIRB/1/4/2020).

Provenance and peer review Not commissioned; externally peer reviewed.

Data availability statement All data relevant to the study are included in the article or uploaded as supplementary information. The raw data, including transcripts of interviews are securely stored in a password protected research data storage system, owned by Bal Umang Drishya Sanstha, India.

Supplemental material This content has been supplied by the author(s). It has not been vetted by BMJ Publishing Group Limited (BMJ) and may not have been peer-reviewed. Any opinions or recommendations discussed are solely those of the author(s) and are not endorsed by BMJ. BMJ disclaims all liability and responsibility arising from any reliance placed on the content. Where the content includes any translated material, BMJ does not warrant the accuracy and reliability of the translations (including but not limited to local regulations, clinical guidelines, terminology, drug names and drug dosages), and is not responsible for any error and/or omissions arising from translation and adaptation or otherwise

Open access This is an open access article distributed in accordance with the Creative Commons Attribution Non Commercial (CC BY-NC 4.0) license, which permits others to distribute, remix, adapt, build upon this work non-commercially, and license their derivative works on different terms, provided the original work is properly cited, appropriate credit is given, any changes made indicated, and the use is non-commercial. See: http://creativecommons.org/licenses/by-nc/4.0/.

ORCID iD

Shanti Raman http://orcid.org/0000-0002-4546-3231

\section{REFERENCES}

1 John's Hopkins University \& Medicine. COVID-19 Dashboard by the center for systems science and engineering (CSSE) at Johns
Hopkins University (JHU). Coronavirus resource centre. Baltimore, 2020. Available: https://coronavirus.jhu.edu/map.html

2 WHO. WHO coronavirus (COVID-19) dashboard. Geneva: World Health Organization, 2021.

3 Ferguson NM, Laydon D, Nedjati-Gilani G. Report 9: impact of nonpharmaceutical interventions (NPIs) to reduce COVID-19 mortality and healthcare demand. London: Imperial College London, 2020.

4 McKibbin W, Fernando R. The global Macroeconomic impacts of COVID-19: seven scenarios. Canberra: Australian National University, 2020.

5 Prasad V, Sri BS, Gaitonde R. Bridging a false dichotomy in the COVID-19 response: a public health approach to the 'lockdown' debate. BMJ Glob Health 2020;5:e002909.

6 Raman S, Harries M, Nathawad R, et al. Where do we go from here? a child rights-based response to COVID-19. BMJ Paediatr Open 2020;4:e000714.

7 UNICEF. Policy brief: the impact of COVID-19 on children. New York: United Nations Children's Fund, 2020.

8 Roberton T, Carter ED, Chou VB, et al. Early estimates of the indirect effects of the COVID-19 pandemic on maternal and child mortality in low-income and middle-income countries: a modelling study. Lancet Glob Health 2020;8:e901-8.

9 WHO. Mental health and psychosocial considerations during the COVID-19 outbreak. Geneva: World Health Organization, 2020.

10 Cardenas MC, Bustos SS, Chakraborty R. A 'parallel pandemic': The psychosocial burden of COVID-19 in children and adolescents. Acta Paediatr 2020;109:2187-8.

11 Patel V. India's tryst with Covid-19. The India forum: Vichar Trust, 2020. https://www.theindiaforum.in/article/indi-s-tryst-covid-19

12 Save the Children. Rights of vulnerable families and children of India under COVID-19: implications for effective response and mitigation strategies. Delhi-NCR, 2020.

13 StataCorp. Stata statistical software. College Station, Texas: StataCorp LLC, 2019.

14 Braun V, Clarke V. Using thematic analysis in psychology. Qual Res Psychol 2006;3:77-101.

15 Cuevas-Parra P, Stephano M. Children's voices in times of COVID-19: Continued child activism in the face of personal challenges. Uxbridge, United Kingdom: World Vision International, 2020.

16 Dulieu N, Burgess M. The hidden impact of COVID-19 on child rights. London: Save the Children International, 2020.

17 Ritz D, O'Hare G, Burgess M. The hidden impact of COVID-19 on child protection and wellbeing. London: Save the Children International, 2020.

18 United Nations Children's Fund (UNICEF). Protecting children from violence in the time of COVID-19: disruptions in prevention and response services. New York: UNICEF, 2020.

19 Loperfido L, Burgess M. The hidden impact of COVID-19 on child poverty. London: Save the Children International, 2020.

20 Gromada A, Richardson D, Rees G. Childcare in a global crisis: the impact of COVID-19 on work and family life. Florence: UNICEF Office of Research - Innocenti, 2020.

21 Chakraborty S. COVID-19 and women informal sector workers in India. Economic \& Political Weekly 2020;55:17-21.

22 Singh R, Mukherjee P. 'Whatever she may study, she can't escape from washing dishes': gender inequity in secondary education - evidence from a longitudinal study in India. Compare 2018;48:262-80.

23 Fikree FF, Pasha O. Role of gender in health disparity: the South Asian context. BMJ 2004;328:823-6.

24 International Child Health Group, Royal College of Paediatrics \& Child Health, Royal College of Paediatrics \& Child Hea. Impact of the COVID-19 pandemic on global child health: joint statement of the International child health group and the Royal College of paediatrics and child health. Arch Dis Child 2021:106:archdischild-2020-320652.

25 Kannan KP. COVID-19 Lockdown: protecting the poor means keeping the Indian economy afloat. Economic \& Political Weekly 2020. [Epub ahead of print: 3 April 2020]. 